\title{
Similarities and differences of COVID-19 and avian infectious bronchitis from molecular pathologist and poultry specialist view point
}

\author{
W.H. Al-Jameel ${ }^{1}$ and S.S. Al-Mahmood ${ }^{2}$ \\ Department of Pathology and Poultry Diseases, College of Veterinary Medicine, University of Mosul, Mosul, Iraq \\ Email: ${ }^{1}$ wasemhana09@uomosul.edu.iq, ${ }^{2}$ saevan981@yahoo.com
}

(Received April 25, 2020; Accepted May 15, 2020; Available online May 15, 2020)

\begin{abstract}
Coronaviruses (CoVs) are important RNA viruses that affect respiratory, gastrointestinal and urinary system of human being and birds. These viruses originated from the subfamily Coronavirinae which genetically includes Alphacoronavirus, Beta coronavirus, Gamma coronavirus and Delta coronavirus. The sequencing analysis of the genome showed that COVID-19 caused by SARS-CoV-2 belongs to Beta coronavirus genus and avian infectious bronchitis caused by IBV comes from Gamma coronavirus genus. Over the past few decades and until now, the world showed that endemic outbreaks of infectious bronchitis in avian caused by IBV. Once more, the world sees the emergence of another new human coronavirus COVID-19 outbreak due to a new strain called SARS-CoV-2. Whole genetic material and comparative genomic analysis exhibited that IBV and SARSCoV-2 have particularly same genomic structures and characteristics. Both have a spike protein in the genome structure which allows that SARS-CoV-2 attaches to their human select cells throughout ACE2 receptors, that are notably reported in the lung and kidney. While IBV uses alpha 2,3 linked sialic acids-dependent manner for bind to the avian tissues which is notably reported in the lung and kidney. The two diseases are produced a pulmonary and urinary infection that lead to sneezing, gasping, respiratory massive destruction, severe pneumonia and renal failure. This review will introduce a general overview of two diseases and describe the phylogeny, epidemiology, pathogenesis, clinical features, autopsy report and microscopic lesions.
\end{abstract}

Keywords: Corona, COVID-19, Avian Infectious Bronchitis, IBV, SARS-CoV-2

DOI: 10.33899/ijvs.2020.126984.1426, (O2020, College of Veterinary Medicine, University of Mosul.

This is an open access article under the CC BY 4.0 license (http://creativecommons.org/licenses/by/4.0/).

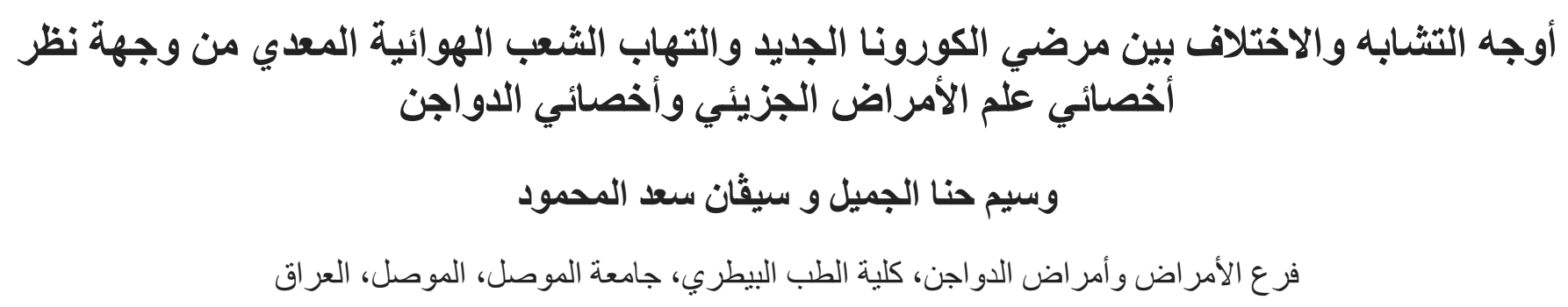

الخلاصة

الفيروسات التاجية هي فيروسات من نوع الرناو التي تصيب الجهاز التنفسي و الهضمي و البولي لدى الإنسان و الطيور ـ تنتمي الفايروسات

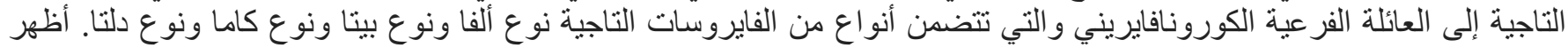

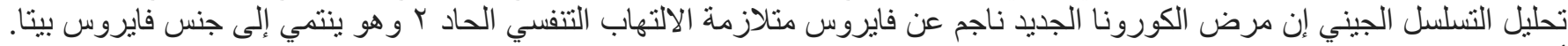

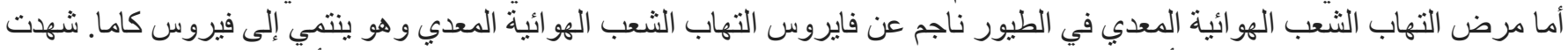

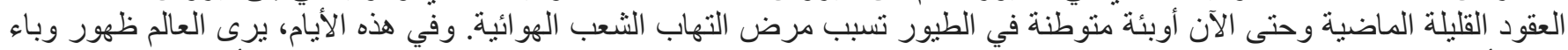

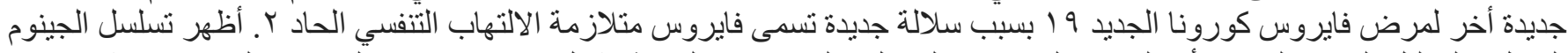

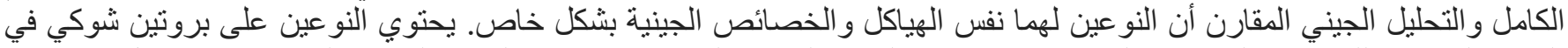

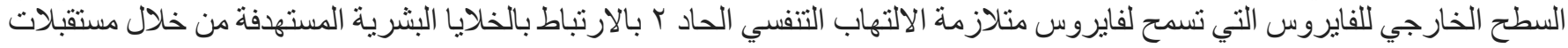




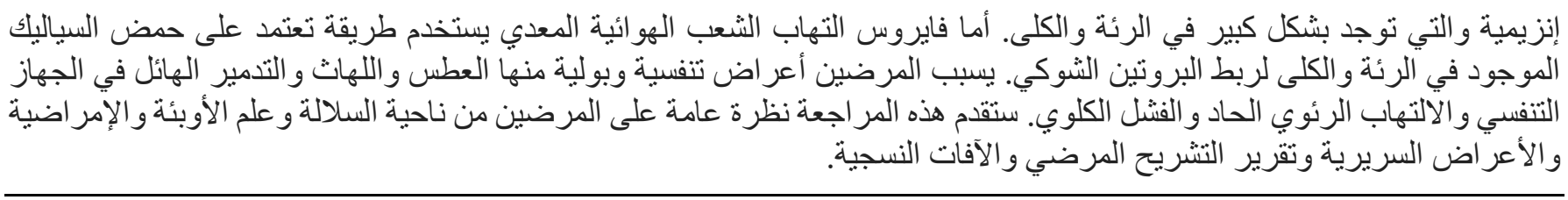

\section{Introduction and background}

Coronaviruses are isolated in a different animals and human beings, that may cause pulmonary, urinary and gastrointestinal diseases of variable harshness. Genetically, CoVs were usually distributed into four different genetic types, Alpha coronavirus, Beta coronavirus, Gamma coronavirus and Delta coronavirus (1). Consequence of RNA viral replication, Coronaviruses own an excessive mutation rates lead the viruses to familiarize with new hosts. The new severe acute respiratory syndrome corona SARS-CoV-like viruses isolated from bats and Pangolins in China have increased attention in the finding of novel-CoVs in both human beings and animals (2). Avian is the warehouse of main developing CoVs especially, Infectious Bronchitis virus (IBV). Because of their flocking behaviour, avian have distribute these initial viruses between themselves and to other birds and humans (3). Avian infectious bronchitis is a disease originated by IBV a Gamma coronavirus that result in condition in the lower part of upper respiratory system in younger ages and renal failure in breeder flocks (4). This disease is highly contagious with high morbidity rate and acute in onset of clinical signs that lead to death with two to three days due to bronchial plagues and renal failure and nephrosis (5). COVID-19 is a new human coronavirus caused by CoV-2 that appeared in December 2019 in China (6). This disease is now extending all over the world for example China, Europe, Australia and North America. COVID-19 is distinguished by a respiratory disorder with a different degree of harshness, from a minor respiratory infection to pneumonia and renal failure (7). COVID-19 and Avian Infectious Bronchitis were generally accompanied by upper and lower respiratory syndrome and renal failure at late stage. In this review our goal is to highlight on the variances between COVID-19 and Avian Infectious Bronchitis with regard to Phylogeny, epidemiology, pathogenesis, and clinical signs.

\section{Phylogeny of COVID-19 and Avian Infectious Bronchitis}

The sequencing analysis of the genome showed that SARS-CoV-2 belongs to Beta coronavirus genus (8) and IBV comes from Gamma coronavirus genus (9). Both Beta coronavirus and Gamma coronavirus genus have open reading frames (ORFs), which encode the non-structural proteins at the 5'-terminal regions of the genome. The 3'- terminal ends of the both genera produce structural proteins (spike (S), envelope (E), membrane (M) and nucleocapsid (N) (10). Based on genomic analysis, assembling verification indicate that SARS-CoV-2 binds to their human target cells by $\mathrm{S}$ protein within angiotensin-converting enzyme 2 (ACE2) receptor, which is found in the lungs and kidney (8), while IBV uses alpha 2,3 linked sialic acids-dependent manner for bind to the avian tissues which is notably reported in the lung and kidney (9). Basically, it has been identified that SARS-CoV-2 has a moderately little mutation degree. However, the virus showed that new mutation on the receptor binding domain of the spikes, which improved its severity by increasing its binding to ACE2 receptors (11). In IBV, the scattered hypervariable regions containing epitopes makes the $S$ protein more variable and mutated (12). The increasing number of frequent gene mutation is a big threat for control of both diseases $(11,13)$. Furthermore, it has showed that an only single mutation on spikes for both viruses, if happens, might rise its severity $(13,14)$.

To understand the infection pathways and designing preventive strategies, it has been presented a genetic network of SARS-CoV-2 genomes as in figure 1 (15) and IBV genomes as in figure 2 (16). It found that gene sequencing of SARS-CoV-2 has three types illustrious by amino acid variations called $\mathrm{A}, \mathrm{B}$, and $\mathrm{C}$. The $\mathrm{A}$ and $\mathrm{C}$ type have discovered outside East Asia, Europe and America. Nevertheless, the B type is the utmost type in Asia and it seems not to have distribute outside Asia (17). On the other hand, phylogenetic network of IBV genome allocated into two important groups, the (a) group involved essentially USA strains, excluding for the $\mathrm{Ck} / \mathrm{Ch} / \mathrm{LDL} / 97 \mathrm{I}$ (Asia and Middle East) (18). The USA group has been segmented into the Mass 41 vaccine and Holte subgroups. The (b) group included just strains of Chinese origin and this was divided in two subgroups (b1 and b2) (18).

\section{Epidemiology of COVID-19 and Avian Infectious Bronchitis}

IBV was firstly described in USA in North Dakota in 1930 when a poultry industry suffered from massive mortalities that referred as infectious laryngotracheitis disease (19). Later in 1931, the first unequivocal report about the disease published by Schalk and Hawn mentioned that this virus belongs to ILT viruses (20). However, in 1936 both Beach and Schalaw described a new virus did not belong to ILT virus using neutralization test (21). In 1937, IBV was 
propagated in egg embryonated chickens (22). In 1941 the first vaccine was invented and developed by Roeckel that lead to well-known Roekel M41 stain of vaccine called later as Massachusetts strain (23). In 1956 a new strain was isolated which known as Connecticut strain which was completely differ genetically from Massachusetts strain indicating presence of many strains of the virus (24). But in 1960s, it was reported that IBV caused high mortalities due to nephritis (25). In the decay of 1990 , a new and fast molecular technique were invented for rapid identification and isolation of the virus (26).

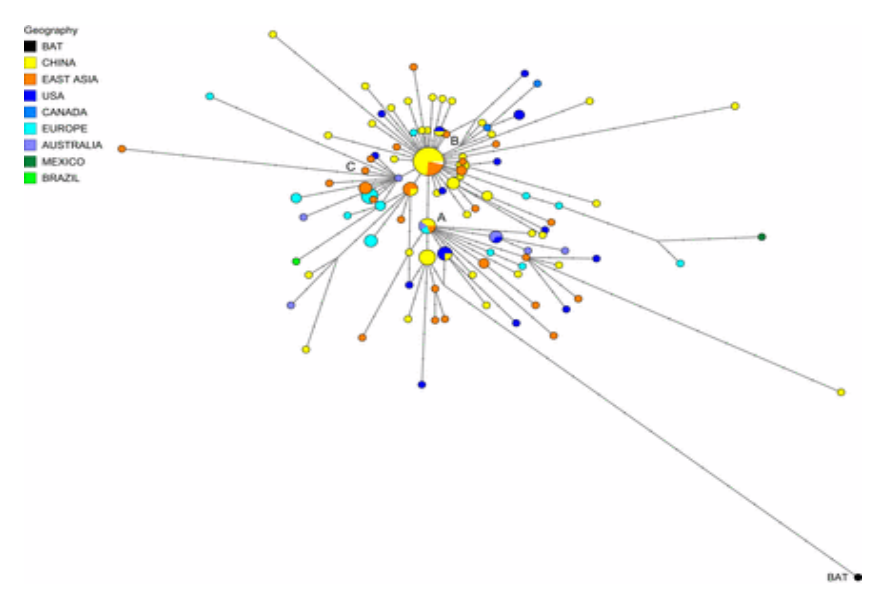

Figure 1: Phylogenetic network of SARS-CoV-2 genomes isolated in many countries.

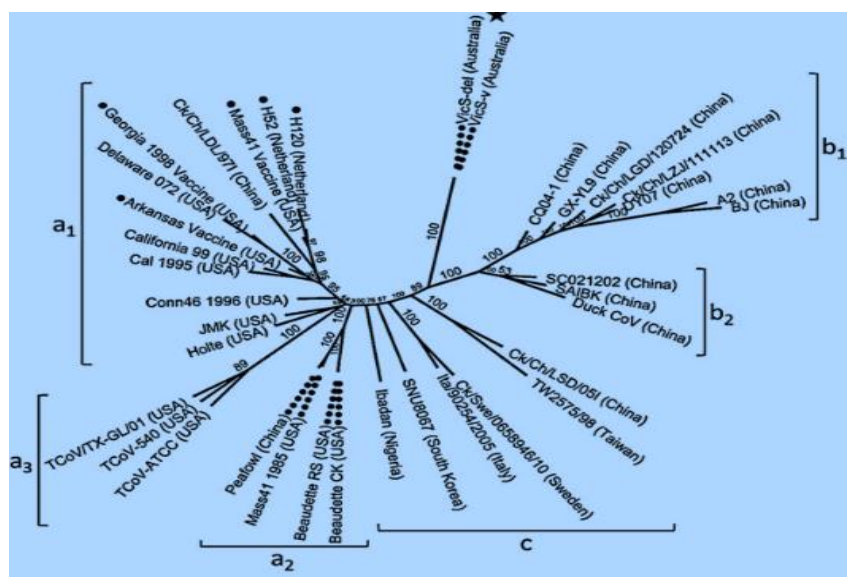

Figure 2: Phylogenetic network of 35 genomes of IBV genomes isolated in many countries.

On the other hand, the first report human Coronavirus infections start in 1960 with many cases treated at that time as a cold like symptoms (27). In 2004, Sever Acute Respiratory Syndrome (SARS) have been reported in 9000 patients and WHO gave state of emergency which called
Sever Acute Respiratory Syndrome Coronavirus (SARS$\mathrm{CoV})(28)$.

In 2012, Saudi Arabia Kingdom reported many cases of acute respiratory syndrome in people with direct contact with camels. After that, phylogenetic analyses showed that a virus the normally infected camel had genome transformation and started infect human which known as Middle East Acute Respiratory Syndrome (MARS) (29).

In late 2019, a case of pneumonia was noted in a Wuhan city, caused by SARS-CoV-2 (30). The epidemic consequently extent to other cities across China then through the world. Studies showed that human-to-human spread in China and all over the world (31). The epidemiological curve has been separated into three stages. The first stage started in the food market at Wuhan city. From the first reported patient in late 2019 to the appearance of new patients outside Wuhan city by beginning of 2020, a whole of more than 40 cases were convinced (30).

The second stage started in the beginning of 2020, noticeable by transmission of the virus from Wuhan to other areas by close-contact spread (32). Outside of China, the first patient was confirmed in Thailand caused by a Wuhan person travelling to Thailand.

In the late of January 2020, many countries were stated a total of more than 800 cases representing that the virus had transfer outside China (33). The third phase started on February 2020, study exhibited that the number of patients accounted for $50-80 \%$ of all convinced cases in Beijing, Shanghai and Jiangsu. By end of February, many confirmed cases were reported in many counties all over the word (Figure 3) (34).

On late of February, the Iraqi health authorities declare the first case of COVID 19 in Iraq. In Mosul city, the first case was reported at 13 march 2020, a young journalist acquired the infection during his residency in Baghdad city, later another five cases were diagnosed with COVID 19 from his own family (35). Until end of April 2020 WHO report more than two million were infected, more than 153 thousand was deceased, and more than 560 thousand was recovered all over the world (36), figure 3 (37).

\section{Economic Importance of COVID-19 and Avian Infectious Bronchitis}

Poultry infection with IBV has a significant influence on poultry industry. This represented by decreases in poultry meat quality and egg production (38). In addition, the eggs from infected chickens can't be hatched due to low hatchability ratio as a result of watery albumen of egg (39). The main economic loss in layer flocks comes from high morbidity reach up to $100 \%$ accompanied by secondary bacterial infection all these lead to decrease or failure in response to vaccination (40). 


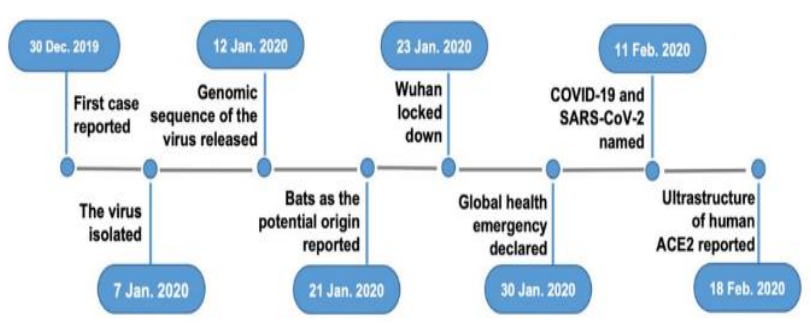

Figure 3: COVID 19, data science perspective.

Similarly, COVID 19 has a huge significant effect on global economy through three main pathways. First one, COVID 19 massive spread all over world causes social distance that lead to series of shutdown and closure in global financial markets, companies, office, industrial factories and this extend to athletic events (41). The second one, obscure in epidemiology and treatment of COVID 19 gives great push to consumer and investors to think twice before any further money spending or investing. The last one, this situation leads to decrease the global trade and effect on oil markets causing deficit in the budget of countries (42), figure 4 (43) and figure 5 (44).

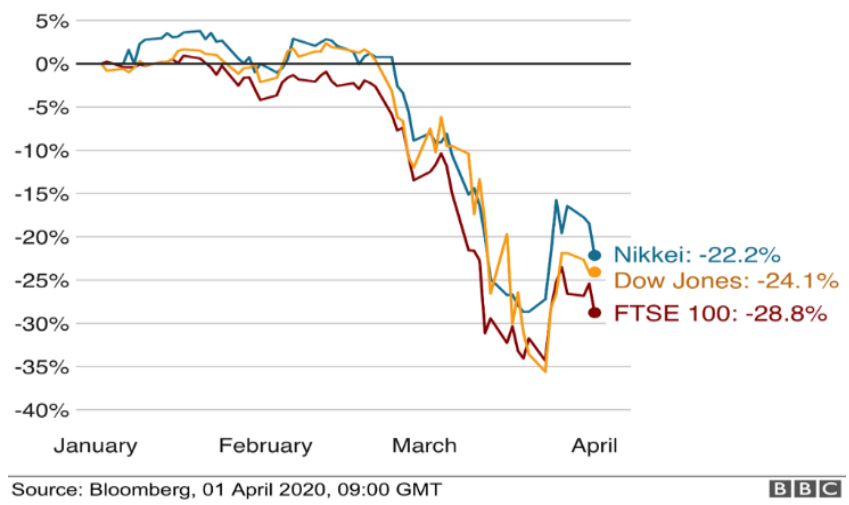

Figure 4: The influence of COVID 19 on stock markets since the start of the outbreak.

\section{Pathogenesis of COVID-19 and Avian Infectious Bronchitis}

Avian Infectious Bronchitis is a world-wide distributed disease affects all ages and aviary species (21). However, it is mores sever in poultry leading to mortalities up to $70 \%$ (45). The IBV replicates in epithelial cells of respiratory and alimentary tract (21). The IBV is known to infect new hosts through aerosol route with incubation period less than 48 hours (46). In addition, the ingestion of virus particle leads to observation of clinical manifestation in 48-72 hours (45). In chickens, IBV has no ability to be transmitted by eggs, but many virus particles can be isolated from egg shells from infected dams (21).

The infected chickens excreted the virus by urine in addition to faecal materials for a long time after recovery from acute diseases (46).

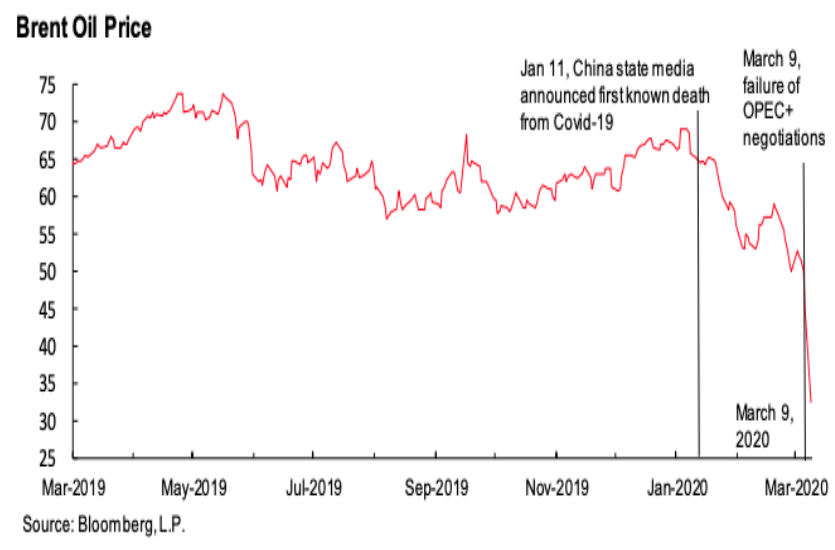

Figure 5: The influence of COVID 19 on oil markets.

Correspondingly, COVID 19 infected all human beings with mortality ratio ranged between 1 death for 10.000 infected persons to 1 death for 100.000 infected persons (47). Nevertheless, it has been revealed that mortality ratio can be $1.13 \%$ outside china to $3.9 \%$ inside china (48). All death resulted from COVID 19 was sever pneumonia infection and less observed cases with renal failure (49). The main route of infection in human with SARS-CoV-2 was reported through aerosol route in which the virus was hold by air and transmitted from infected person to healthy person by sneezing or coughing (50). There is little understanding of infant COVID-19 infections by intrauterine transmission of SARS-CoV-2. However, it has been reported a case of pregnant women had birth with COVID 19 after 3 to 15 days after birth. Nevertheless, this result in not conclusive because the current endemic status of the virus in which babies can get infection after birth (51).

It has been stated that SARS-CoV-2 still excretes from infected person for about 15 days after recovery form clinical manifestation. In addition, the nasal swabs will still positive for virus particle for at least 10 days after overcome the clinical phase of diseases $(49,50)$.

The SARS-CoV-2 infection in respiratory system causes what is termed as cytokines storm by influx production of interleukin 6 (IL-6) which causes massive inflammatory reaction in epithelial tissues of lung.

Furthermore, viral replication leads to cell damage that will release acute phase protein (thermoregulation) leading to increase in body temperature $(52,53)$. 


\section{Clinical features of COVID-19 and Avian Infectious Bronchitis}

Clinical signs in cases infected with IBV can be divided upon age of infected poultry. In younger ages, the main clinical signs are sneezing, gasping, sounds in the trachea and discharge from eye and nose (54). Subsequent, the disease will develop to infect renal tissue and lead to ruffled feathers, dropping of wings, increase in water uptake, urolithiasis and high mortality rate (55). In laying flocks, the infection will cause changes in production line of eggs that represent by decrease in egg production and changes in the internal quality of eggs (56). The eggs produced by infected layer flocks with IBV are characterized by flattened eggs, broken calcium shell, watery egg albumin, and mixing both thick and thin egg albumin (57).

In COVID 19 clinical signs are varied and uncertain ranging from mild to severe respiratory illness and even death due to failure of respiration (58). In adult, it has been recorded signs associated with server pneumonia, fever, dry coughing, dyspnoea, headache and less commonly diarrhoea (59). The people with mild clinical signs can return to normal activity with 6 to 10 days. On other hands, individual who shows severe respiratory pneumonia may be recorded death due to respiratory massive destruction as a result of virus replication in endothelial cells of alveoli (60). In paediatric individual who infected with SARS-CoV-2, the clinical symptoms included congestion of pharynx $1 \%$, sore throat $1 \%$, fever $13 \%$ and coughing 3.8\% (61). In cases end with death the symptoms start as dry cough, progress to severely affecting pneumonia, coagulopathy, septic shock (62), acute onset of fever, dizziness, muscle spasm, vomiting, nausea, diarrhea and chest pain $(63,64)$.

\section{Post mortem lesions of IBV in poultry and Autopsy report of COVID 19 patients}

The post mortem changes in poultry can be divided into two forms depend upon age of affected poultry. In young ages, the changes showed different types of exudate in trachea depend upon progress of diseases in which it is serous then developed to be catarrhal then ended as caseous exudate that causes obstruction to the air passages with signs of neck stretching and gasping (65). The lung of dead poultry showed sever pneumonia with congestion and haemorrhage, nephritis, increase in the size of kidney, white chalky material on cloaca (66). In layer flocks, yolk material can be found in abdominal cavity with cystic oviduct at left side (67-70) and shorten in oviduct (71) as in figure 6 (72).

The most autopsy recommendation and protocol in case of COVID 19 directed the pathologists into two different protocols. Some report advises workers to omit the full autopsy procedure and limit their work upon obtaining tissue samples from lung and other affected organs. However, other reports advise pathologists to apply full autopsy protocol with special emphasising on lung and kidneys (49). In general, the main necropsy finding present in chest cavity associated with pleurisy, different stages of pneumonia, significant frequency for consolidation stage, massive oedema, and significant increase in size and weight of lung (73) as in figure 7 (74). It has been shown that the chest autopsy in patient died from COVID 19 is characterized by lung weight ranged from 680 to 1050 grams, the arteries in hilum region are free from embolic thrombi, thickening in bronchi and bronchiole walls, firm and oedematous lung, scattered red to black spots on lung tissue represented by haemorrhage and lung appeared frankly (72).

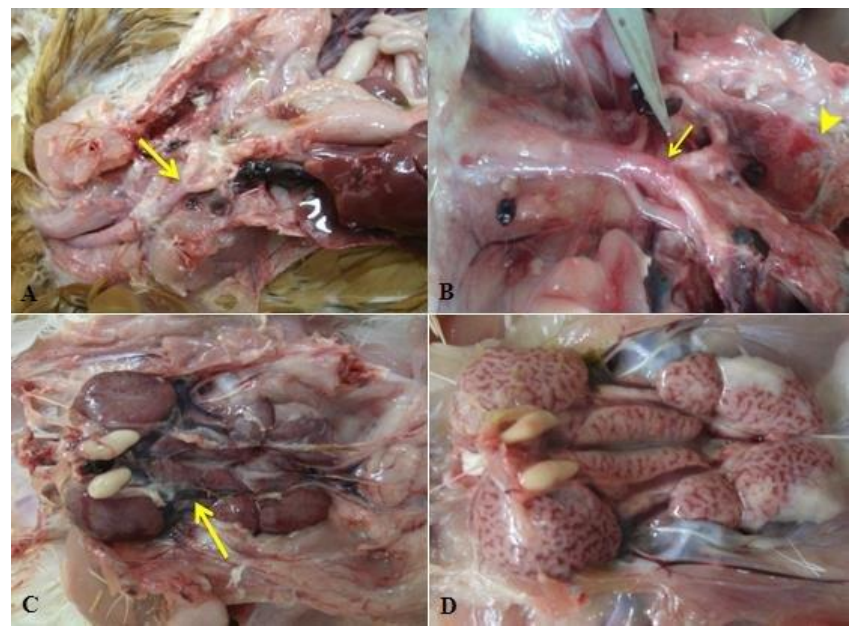

Figure 6: Post mortem lesions of IBV in poultry.

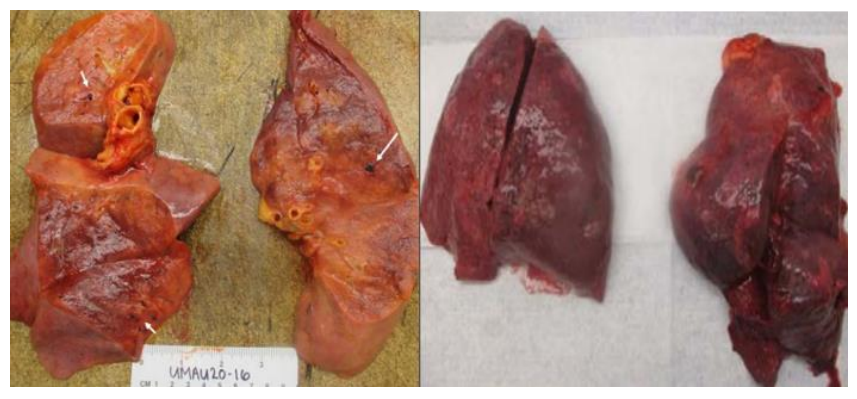

Figure 7: Lung of COVID 19 patients.

\section{Microscopic lesions caused by Infectious Bronchitis in poultry and COVID 19 in human}

The microscopic lesions caused by IBV appear on the mucosa of trachea bronchia and kidney. In trachea, the endothelia cells loss their cilia and transformed under effect of virus replication from columnar to cuboidal cells and 
infiltration of cell responsible for viral fights include lymphocytes and heterophils, as in Figure 8 (75).

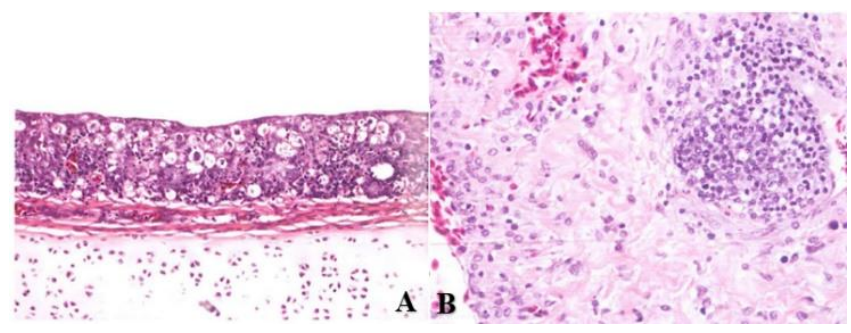

Figure 8: Infectious bronchitis histopathology in (a) trechea and (b) lung.

Later the affected endothelial cells and mucosa of trachea and bronchioles were hyperplastic with massive infiltration of macrophages in lamina propria layer, lymphocytes and fibrinous exudate. After 48 hours, the fibrinous exudate transformed to caseous exudate which adhered to the lumen and lead to complete or partial closure (76). In kidney, there are many reactive responses to viral replication result in vacuolic degeneration and coagulative necrosis of the epithelial cell of renal tubules lead to sloughing and desquamation in the lumen of affected tubules (77). In layer flocks, the microscopic lesions that present in oviduct showed that dysplasia of ciliated columnar epithelial cells of oviduct into simple cuboidal or squamous cells with losing the ciliated function due to continuous irritation caused by virus replication (78). In addition, the microscopic lesions show infiltration of lymphatic cells and plasma cells in all layer of oviduct, dilatation in glands, oedema and fibrinoid necrosis in mucosa of all oviducts (71).

In humans infected with SARS-CoV-2, the histopathological examination in lung showed massive necrotic changes with slough and desquamation of cells in lumen as in figure 9 (79).

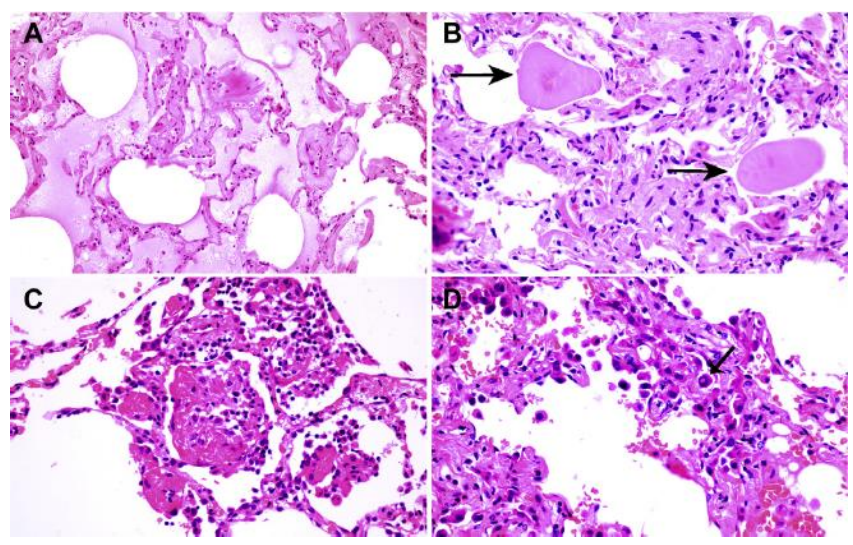

Figure 9: COVID histopathology in lung and alevoli.
Furthermore, the microscopic lesions showed hyperplasia of pneumocytes type II, deposition of fibrin strand in the interstitial tissues and infiltration of inflammatory cells mainly lymphocytes and plasma cells $(79,80)$. While in kidney, the lesions composed from massive cogaulative necrosis in epithelial cell in proximal renal tubules, losing their brush borders, hemosiderin pigmentation, hyaline casts, infiltration of inflammatory cells specially lymphocytes, plasma cell (81).

\section{Vaccination against COVID-19 and Avian Infectious Bronchitis}

Various techniques have been accepted in the manufacturing of Coronavirus vaccines, best of these techniques are target the s-protein which is the main inducer of antibodies, however, live-attenuated vaccines have effectively used depend on inactivation of non-structural proteins in SARS-CoV (82). It has been proposed that IBV vaccine may be used for SARS-CoV (83). Because of the avian coronavirus has high genetic connection and uses the same mechanism for infection to COVID-19, therefore, it was recommended that IBV vaccine could be deliberated a choice for COVID-19 once testing its safety (84).

\section{Conclusion}

After these short comparisons between two diseases, we conclude that, both diseases are characterized by high infectious rate and high mortality rate. These diseases are infecting all ages except in COVID 19 it was less infects on younger ages. Both diseases benefit from immune suppression status of hosts and affect respiratory and renal system causing pathological changes in lung and kidney which lead to an uncontrolled mortality rate between poultry and human. The biggest challenges now represented by obscure mutations in infectious bronchitis virus in chickens to be able to cause infection in human. Since the last decay diseases especially avian influenza viruses have the same pathways, this will be catastrophic losses in poultry industry and human beings.

\section{Acknowledgments}

We would to express our thanks to College of Veterinary Medicine, University of Mosul for endless intellectual support and benevolent assistance in completing the modest review paper.

\section{Conflict of interests}

Authors declares that they have no conflict of interest regarding publishing this review article. 


\section{References}

1. Brian DA, Baric RS. Coronavirus genome structure and replication. Curr Top Microbiol Immunol. 2005;287:1-30. 10.1007\%2F3-54026765-4_1

2. Guan Y. Isolation and characterization of viruses related to the SARS coronavirus from animals in southern china. Sci. 2003;302(5643):2768. 10.1126/science. 1087139

3. Woo PC, Lau SK, Lam CS, Lai KK, Huang Y, Lee P, Geraldine SM, Luk KC, Dyrting KH, Chan Kwok YY. Comparative analysis of complete genome sequences of three avian coronaviruses reveals a novel group 3c coronavirus. J Virol. 2008;83(2):908-17. 10.1128/jvi.01977-08

4. Domanska BK, Jacukowicz A, Lisowska A, Wyrostek K, Minta Z. Detection and molecular characterization of infectious bronchitis-like viruses in wild bird populations. Avi Pathol. 2014;43(5):406-13. 10.1080/03079457.2014.949619

5. Singh IP, Cunningham CH. Differentiation of avian infectious bronchitis virus isolates by thermal sensitivity. Avi Dis. JSTOR. 1978;22(3):440. 10.2307/1589299

6. Salzberger B, Gluck T, Ehrenstein B. Successful containment of COVID-19: the WHO-Report on the COVID-19 outbreak in China. Infect. 2020;48(2):151-3. 10.1007/s15010-020-01409-4

7. Chea MV. COVID-19, Australia: Epidemiology Report 7: Reporting week ending 19:00 AEDT 14 March 2020. Comm Dis Intel. 2020;44.14. $10.33321 /$ cdi. 2020.44 .23

8. Sarvesh S, Himesh S, Jitender KM, Sanjay K, Vimal K. Corona: A review on current clinical sympathetic. J Appl Med Sci. 2020; 8(3): 1054-1061. 10.36347/sjams.2020.v08i03.049.

9. Wickramasinghe IN, de Vries RP, Crone A, de Haan CA, Verheije $\mathrm{MH}$. Binding of avian coronavirus spike proteins to host factors reflects virus tropism and pathogenicity. J Virol.2011;85(2011):89038912. 10.1128/JVI.05112-11

10. Yu Chen, Qianyun Liu, Deyin Guo. Emerging coronaviruses: Genome structure, replication, and pathogenesis First published: 22 January 2020. https://doi.org/10.1002/jmv.25681

11. Yong J, Gangxu S, Yujuan Z, Keng SH, Hsing YH, Wei SH, Chih HY, Chengdao L, Wei LW. Analysis of the mutation dynamics of SARS-CoV-2 reveals the spread history and emergence of RBD mutant with lower ACE2 binding affinity. Cold Spring Har Lab. 2020;11:1-2. 10.1101/2020.04.09.034942

12. Mo ML, Hong SM, Kwon HJ, Kim IH, Song CS, Kim JH. Genetic diversity of spike, $3 \mathrm{a}, 3 \mathrm{~b}$ and e genes of infectious bronchitis viruses and emergence of new recombinants in Korea. Viruses. 2013;5(2):550567. 10.3390/v5020550

13. Wan Y, Shang J, Graham R, Baric RS, Li F. Receptor recognition by novel coronavirus from 298 Wuhan: An analysis based on decade-long structural studies of SARS. J Virol. 2020;94(7):1-2. 10.1128/jvi.00127-20

14. Siham F, Mehdi EL, Mariette D, Chafiqa L, Saad ISK, Jens HK, Slimane K, Mohammed EH, My ME. Phylogenetic analysis of avian infectious bronchitis virus S1 glycoprotein regions reveals emergence of a new genotype in Moroccan broiler chicken flocks. Virol J. 2015;12:116. 10.1186/s12985-015-0347-8

15. Japan ECM. Onset for COVID-19: Telephone consultations for cases with severe respiratory failure caused by COVID-19. J Inten Care. 2020;8(1):1-3. 10.1186/s40560-020-00440-9

16. José AQ, Philip FM, Sang WL, Kylie AH, Carol AH, Alistair RL, Mauricio JC, Paola KV, Glenn FB. Analysis of the complete genomic sequences of two virus subpopulations of the Australian infectious bronchitis virus vaccine. Avi Pathol. 2015:44(3): 182-191. 10.1080/03079457.2015.1022857

17. Peter F, Lucy F, Colin R, Michael FC. Phylogenetic network analysis of SARS-CoV-2 genomes. Proc Nat Acad Sci. 2020;2:1-5 10.1073/pnas.2004999117
18. Abd ED, Saad A, Mohammad Z. Presence of infectious bronchitis virus strain $\mathrm{CK} / \mathrm{CH} / \mathrm{LDL} / 97 \mathrm{I}$ in the Middle East. Inter Schol Res Notices. 2012;201721:1-6. 10.5402/2012/201721

19. Komorov A, Grasovsky YS. Notes on a specific infectious respiratory disease affecting baby chicks (IB). Vet J. 1941;97(12):407-10. 10.1016/s0372-5545(17)34106-8

20. Schalk AF, Hawn MC. An apparent new respiratory disease of baby chicks. J Am Vet Med Assoc. 1931;78:413-422.

21. Fabricant J. The early history of infectious bronchitis. Avi Dis. JSTOR. 1998;42(4):648. 10.2307/1592697

22. Beach JR, Schalm OW. A Filterable Virus, distinct from that of laryngotracheitis, the cause of a respiratory disease of chicks. Poult Sci. 1936;15(3):199-206. 10.3382/ps.0150199

23. Rosenwald AS. Poultry disease control in California. Poult Sci. 1949;28(2):173-81. 10.3382/ps.0280173

24. Hopkins SR. Serologic and immunologic properties of a recent isolate of infectious bronchitis virus. Avi Dis. 1969;13(2):356. $10.2307 / 1588504$

25. Pohl R. The histopathogenesis of the nephrosis- nephritis syndrome. Avi Pathol. 1974;3(1):1-13. 10.1080/03079457409353810

26. Kwon HM, Jackwood MW, Gelb J. Differentiation of infectious bronchitis virus serotypes using polymerase chain reaction and restriction fragment length polymorphism analysis. Avi Dis. 1993;37(1):194. 10.2307/1591474

27. Resta S. Isolation and propagation of human enteric corona virus. Ped Infect Dis J. 1986;5(2):284. 10.1097/00006454-198603000-00042

28. Chen CJ, Chien YC, Yang HI. Epidemiology and control of severe acute respiratory syndrome (SARS) outbreak in Taiwan. World Sci. 2003;1:20-22. 10.1142/9789812388902 0017

29. Monecke S, Skakni L, Hasan R, Ruppelt A, Ghazal SS, Hakawi A. Characterisation of MRSA strains isolated from patients in a hospital in Riyadh, Kingdom of Saudi Arabia. BMC Microbiol. 2012;12(1):146. 10.1186/1471-2180-12-146

30. Li Q. Early transmission dynamics in Wuhan, China, of novel coronavirus-infected pneumonia. N Engl J Med. 2020;382(13):11991207. 10.1056/NEJMoa2001316

31. Bogoch II. Pneumonia of unknown aetiology in Wuhan, China: Potential for international spread via commercial air travel. J Travel Med. 2020;27(3):1-7. 10.1093/jtm/taaa008

32. Adhikari SP, Meng S, Wu YJ, Mao YP, Ye RX, Wang QZ, Zhou H. Epidemiology, causes, clinical manifestation and diagnosis, prevention and control of coronavirus disease (COVID-19) during the early outbreak period: a scoping review. Infect Dis Poverty. 2020;9(1):1-7 10.1186/s40249-020-00646-X

33. Liu YC, Liao CH, Chang CF, Chou CC, Lin YR. A locally transmitted case of SARS-CoV-2 Infection in Taiwan. $\mathrm{N}$ Engl $\mathrm{J}$ Med. 2020;382(11):1070-2. 10.1056/nejmc2001573

34. Chang D, Lin M, Wei L, Xie L, Zhu G, Dela Cruz CS. Epidemiologic and clinical characteristics of novel coronavirus infections involving 13 patients outside Wuhan, China. JAMA. 2020; 17;323(11):1092. 10.1001/jama.2020.1623

35. WHO. Situation report - 60, Coronavirus disease 2019 (COVID-19), 20 March 2020. New York: WHO reports; 2020. 1 p. [Available here]

36. WHO. Situation report - 90, Coronavirus disease 2019 (COVID-19), 20 March 2020. New York: WHO reports; 2020. 1 p. [Available here]

37. Yi Ye, Philip NP, Lagniton SY, Enqin Li, Ren HX. COVID-19: What has been learned and to be learned about the novel coronavirus disease. Inter J Biol Sci. 2020;10(2020):1753-1766. 10.7150/ijbs.45134.

38. Cook JKA, Davison TF, Huggins MB, McLaughlan P. Effect of in ovo bursectomy on the course of an infectious bronchitis virus infection in line c white leghorn chickens. Arch Virol. 1991;118(3-4):225-234. $10.1007 / \mathrm{bf} 01314032$

39. Sevoian M, Levine PP. Effects of infectious bronchitis on the reproductive tracts, egg production, and egg quality of laying chickens. Avi Dis. 1957;1(2):136. 10.2307/1587727

40. Cavanagh D, Mawditt K, Sharma M, Drury SE, Ainsworth HL, Britton P. Detection of a coronavirus from turkey poults in Europe genetically 
related to infectious bronchitis virus of chickens. Avi Pathol. 2001;30(4):355-68. 10.1080/03079450120066368

41. Martin FM. Economic realities and consequences of the COVID-19 pandemic-part II: The economy and fiscal policy. Econom Synop. 2020;20(11):1. 10.20955/es.2020.11

42. Vladislav I. How the COVID- 19 epidemic will impact the economy. Curr Digest Russian Press. 2020;72(007):18-18. $10.21557 / \mathrm{dsp} .58004784$

43. https://www.bbc.com/news/business-51706225

44. https://voxeu.org/article/oil-price-wars-time-covid-19

45. Crinion RAP, Hofstad MS. Pathogenicity of four serotypes of avian infectious bronchitis virus for the oviduct of young chickens of various ages. Avi Dis. 1972;16(2):351. 10.2307/1588800

46. Cunningham CH, Spring MP, Nazerian K. Replication of avian infectious bronchitis virus in african green monkey kidney cell line VERO. J Gen Virol. 1972;6(3):423-7. 10.1099/0022-1317-16-3-423

47. Baud D, Qi X, Nielsen SK, Musso D, Pomar L, Favre G. Real estimates of mortality following COVID-19 infection. Infect Dis. 2020. 10.1016/s1473-3099(20)30195-X

48. Zhang Z, Yao W, Wang Y, Long C, Fu X. Wuhan and Hubei COVID19 mortality analysis reveals the critical role of timely supply of medical resources. J Infect. 2020. 10.1016/j.jinf.2020.03.018

49. Hanley B, Lucas SB, Youd E, Swift B, Osborn M. Autopsy in suspected COVID-19 cases. J Clin Pathol. 2020;20:206522. 10.1136/jclinpath2020-206522

50. Guo YR, Cao QD, Hong ZS, Tan YY, Chen SD, Jin HJ. The origin, transmission and clinical therapies on coronavirus disease 2019 (COVID-19) outbreak - an update on the status. Military Med Res. 2020;7(1):1. 10.1186/s40779-020-00240-0

51. Chen H, Guo J, Wang C, Luo F, Yu X, Zhang W. Clinical characteristics and intrauterine vertical transmission potential of COVID-19 infection in nine pregnant women: a retrospective review of medical records. Lancet. 2020;395(10226):809-15. 10.1016/s01406736(20)30360-3

52. Di Gennaro F, Pizzol D, Marotta C, Antunes M, Racalbuto V, Veronese N. Coronavirus Diseases (COVID-19) current status and future perspectives: A narrative review. Inter J Enviro Res Pub Heal. 2020;17(8):2690. 10.3390/ijerph17082690

53. Carcillo JA, Shakoory B. Cytokine storm and sepsis-induced multiple organ dysfunction syndrome. Cytok Storm Synd. 2019;451-64. 10.1007/978-3-030-22094-5 27

54. Bijlenga G, Cook JKA, Gelb, Jr J, Wit JJ de. Development and use of the $\mathrm{H}$ strain of avian infectious bronchitis virus from the Netherlands as a vaccine: A review. Avi Pathol. 2004;33(6):550-7. 10.1080/03079450400013154

55. Albassam MA, Winterfield RW, Thacker HL. Comparison of the nephropathogenicity of four strains of infectious bronchitis virus. Avi Dis. 1986;30(3):468. 10.2307/1590408

56. Alexander DJ, Gough RE. Isolation of avian infectious bronchitis virus from experimentally infected chickens. Res Vet Sci. 1977;23(3):344-7. 10.1016/s0034-5288(18)33129-1

57. Cook KA, Otsuki K, da Silva Martins NR, Ellis MM, Huggins MB. The secretory antibody response of inbred lines of chicken to avian infectious bronchitis virus infection. Avi Pathol. 1992;21(4):681-92. 10.1080/03079459208418890

58. Phan T. Novel coronavirus: From discovery to clinical diagnostics. Infect Gen Evol. 2020;79:104211. 10.1016/j.meegid.2020.104211

59. Hamer D. F1000 Prime recommendation of genomic characterisation and epidemiology of 2019 novel coronavirus: implications for virus origins and receptor binding. Biomed literate. 2020;23:1. 10.3410/f.737287248.793571514

60. Russell CD, Millar JE, Baillie JK. Clinical evidence does not support corticosteroid treatment for 2019-nCoV lung injury. Lancet. 2020;395(10223):473-5. 10.1016/s0140-6736(20)30317-2

61. Urso DL. Coronavirus Disease 2019 (COVID-19): A brief report. Clin Manage. 2020;14(1):1. 10.7175/cmi.v14i1.1467
62. Chen N, Zhou M, Dong X, Qu J, Gong F, Han Y. Epidemiological and clinical characteristics of 99 cases of 2019 novel coronavirus pneumonia in Wuhan, China: a descriptive study. Lancet. 2020;395(10223):507-13. 10.1016/s0140-6736(20)30211-7

63. Gorbalenya AE, Baker SC, Baric RS, de Groot RJ, Drosten C, Gulyaeva AA. Severe acute respiratory syndrome-related coronavirus: The species and its viruses - a statement of the coronavirus study Group. Cold Spring Harbor Lab. 2020;11:1. 10.1101/2020.02.07.937862

64. Ren LL, Wang YM, Wu ZQ, Xiang ZC, Guo L, Xu T. Identification of a novel coronavirus causing severe pneumonia in human. Chinese Med J. 2020;1. 10.1097/cm9.0000000000000722

65. Cumming RB. Infectious avian nephrosis (uraemia) in Australia. Australian Vet J. 1963;39(9):360-360. 10.1111/j.17510813.1963.tb04369.x

66. Ziegler AF, Ladman BS, Dunn PA, Schneider A, Davison S, Miller PG, Lu H, Weinstock D, Salem M, Eckroade RJ, Gelb JJ. Nephropathogenic infectious bronchitis in Pennsylvania chickens 1997-2000. Avi Dis. 2002;46:847-58. 10.1637/0005-2086(2002)046[0847:nibipc]2.0.co;2

67. Benyeda Z, Mató T, Süveges T, Szabó É, Kardi V, Abonyi TZ. Comparison of the pathogenicity of QX-like, M41 and 793/B infectious bronchitis strains from different pathological conditions. Avi Pathol. 2009;38(6):449-56. 10.1080/03079450903349196

68. Chew PH, Wakenell PS, Farver TB. Pathogenicity of attenuated infectious bronchitis viruses for oviducts of chickens exposed in ovo. Avi Dis. 1997;41(3):598. 10.2307/1592150

69. Crinion RAP. Egg quality and production following infectious bronchitis virus exposure at one day old. Poult Sci. 1972;51(2):582-5. 10.3382/ps.0510582

70. Jones RC, Jordan FTW. Persistence of virus in the tissues and development of the oviduct in the fowl following infection at day old with infectious bronchitis virus. Res Vet Sci. 1972;13(1):52-60. 10.1016/s0034-5288(18)34088-8

71. Sevoian M, Levine PP. Effects of infectious bronchitis on the reproductive tracts, egg production, and egg quality of laying chickens. Avi Dis. 1957;1(2):136. 10.2307/1587727

72. Swayne DE, Boulianne M, Logue CM, McDougald LR, Nair V, Suarez DL. Diseases of Poultry. New York: Wiley; 2019. 176-213 p. 10.1002/9781119371199

73. Xu Z, Shi L, Wang Y, Zhang J, Huang L, Zhang C. Pathological findings of COVID-19 associated with acute respiratory distress syndrome. Res Med. 2020;8(4):420-2. 10.1016/s2213-2600(20)30076$\mathrm{x}$

74. Patel J, Sheppard MN. Pathological study of primary cardiac and pericardial tumours in a specialist UK Centre: surgical and autopsy series. Cardiovas Pathol. 2010;19(6):343-52. 10.1016/j.carpath.2009.07.005

75. Wallner PE. Avian histopathology. JSTOR. 1987;1(4):158. $10.2307 / 27670278$

76. Toro H, Reyes E, Redmann T, Kaleta EF. Local and systemic specific antibody response of different chicken lines after ocular vaccination against infectious bronchitis. J Vet Med. 1996;43(1-10):449-54. 10.1111/j.1439-0450.1996.tb00339.x

77. Chen BY, Hosi S, Nunoya T, Itakura C. Histopathology and immunohistochemistry of renal lesions due to infectious bronchitis virus in chicks. Avi Pathol. 1996;25(2):269-83. $\underline{10.1080 / 03079459608419141}$

78. Raj GD, Jones RC. Infectious bronchitis virus: Immunopathogenesis of infection in the chicken. Avi Pathol. 1997;26(4):677-706. $10.1080 / 03079459708419246$

79. Tian S, Hu W, Niu L, Liu H, Xu H, Xiao SY. Pulmonary pathology of early-phase 2019 novel coronavirus (COVID-19) pneumonia in two patients with lung cancer. J Thorac Oncol. 2020;1. 10.1016/j.jtho.2020.02.010

80. Zhang H, Zhou P, Wei Y, Yue H, Wang Y, Hu M. Histopathologic changes and SARS-CoV-2 immunostaining in the lung of a patient with COVID-19. Ann Inter Med. 2020;12:1. 10.7326/m20-0533 
81. Su H, Yang M, Wan C, Yi LX, Tang F, Zhu HY. Renal histopathological analysis of 26 post-mortem findings of patients with COVID-19 in China. Kidney Inter. 2020;2:1. 10.1016/j.kint.2020.04.003

82. Graham RL, Donaldson EF, Baric RS. A decade after SARS: Strategies for controlling emerging coronaviruses. Nat Rev Microbiol. 2013;11(12):836-48. 10.1038/nrmicro3143
83. Bijlenga G. Proposal for vaccination against SARS coronavirus using avian infectious bronchitis virus strain $\mathrm{H}$ from the Netherlands. J Infect. 2005;51(3):263-65. 10.1016/j.jinf.2005.04.010

84. Zhang L, Liu Y. Potential interventions for novel coronavirus in China: A systemic review. J Med Virol. 2020;92(5):479-490. 10.1002/jmv.25707 